Jurnal Agroteknologi, Vol. 8 No. 1, Agustus 2017: $23-28$

\title{
KERAGAMAN VIABILITAS BENIH 20 GENOTIPE PEPAYA (Carica papaya L.)
}

\author{
(Seed Viability Diversity of 20 Papaya's Genotypes) \\ NOFLINDAWATI, TRI BUDIYANTI DAN DEWI FATRIA \\ Balai Penelitian Tanaman Buah Tropika -Solok Sumatera Barat \\ JIn Raya Solok-Aripan KM 10 Solok Sumatera Barat. \\ Email: noflindawatialfacik@gmail.com
}

\begin{abstract}
Germination problems in the commerce in general are the seeds will experience a period save on condition of sub optium. The seeds that have high viability and vigor which is expected to be passed on to seed derivatives that are genetically seed quality can be maintained. The study aims to determine the diversity of physiological seed quality of 20 genotypes of papaya collection Tropical Fruit Research Institute. Research conducted at the KP Sumani Balitbu Tropika 2015. Materials: 20 genotype papaya seeds. Research using a randomized block design with three replications treatment of 20 genotypes of papaya. Results of the study showed germination of 20 genotypes of papaya tested ranged from 33$93 \%$, vigor index among 11-81\%, the maximum growth potential of among 16-100\%, and the plant fresh weight ranges from $0.5-15 \mathrm{~g}$. Genetic diversity germination, the seeds of papaya is very high. Characters germination, vigor index and wet weights, the character is inherited as too high the heritability.
\end{abstract}

Keywords : gemination, papaya,seed, heritability

\section{PENDAHULUAN}

Pepaya (Carica papaya L.) diperbanyak melalui benih generatif, sehingga perlu dipertahankan mutu benih selama penyimpanan agar vigor dan viabilitas benih tidak turun secara dratis. Menurut Mugnisyah (2000) mutu benih dapat dikelompokkan menjadi tiga yaitu mutu fisik, mutu fisiologis dan mutu kesehatan (pathologis). Mutu benih merupakan faktor fenotipe, yang dipengaruhi faktor genetik dan lingkungan selama dalam lintasan viabilitas benih antara lain saat pembentukan, pemasakan, panen, pasca panen, penyimpanan, sampai benih ditanam.

Peningkatan mutu benih dapat disinergikan dengan kegiatan perakitan suatu varietas (pemuliaan), dimana sebelum melakukan perakitan varitas menjadi varietas unggul maka aspek mutu benih yang akan dihasilkan perlu diperhatikan. Penurunan mutu benih dapat terjadi selama penyimpanan dan dalam proses tata niaga, kerugian akibat penurunan mutu benih selama tata niaga benih mencapai 25\% per tahun (Copeland dan Mc Donald 2001 ). Informasi mengenai mutu benih didapatkan dari hasil pengujian, mutu suatu benih menjadi jaminan bagi konsumen untuk keberhasilan produksi suatu tanaman. Hasil pengujian langsung dapat tercermin pada fase kecambah atau bibit. Baihaki (2009) menyatakan benih sebagai bahan perbanyakan harus diperhatikan mutunya karena dapat mempengaruhi produksi hingga $60 \%$. Mutu benih tidak saja dipengaruhi oleh berbagai proses produksi dan pasca panen benih, namun juga oleh faktor genetik (Wirnas 2012). Berbagai hasil penelitian menunjukkan bahwa terdapat keragaman mutu benih atau karakter yang berhubungan dengan mutu benih. Keragaman mutu benih dikendalikan oleh faktor genetik sehingga diwariskan pada generasi berikutnya (Marwanto, 2003; Akram el al., 2007; Isemura, 2007; Sacidi, 2008; Divakara et al., 2010, Wirnas 2012).

Menurut Fehr (1987) heritabilitas merupakan perbandingan antara ragam aditif dengan ragam fenotipe. Heritabilitas digunakan untuk memprediksi nilai fenotip yang sangat membantu kegiatan pemuliaan tanaman. Nilai ragam fenotip bersifat kuantitatif berbeda dengan ragam genotip yang hanya bias ditentukan melalui penampakan ragam fenotip dari generasi ke generasi berikutnya. Apabila kualitas fenotipe bagus maka dapat disimpulkan bahwa pohon tersebut memiliki potensi genetik untuk tumbuh bagus (Schmidt, 2000).

Balai Penelitian Tanaman Buah Tropika memiliki koleksi plasma nutfah pepaya yang sangat beragam. Koleksi tersebut berasal dari hasil eksplorasi, hibridisasi dan penggaluran sehingga ada beberapa yang sudah dirilis sebagai VUB pepaya diantaranya verietas Merah Delima, Agri Solinda, Carvita Agrihorti dan Dapina. Kegiatan pengkayaan 
terus dilakukan untuk mendaptkan keragaman genetik untuk perakitan pepaya dimasa datang sesuai dengan preferensi pasar. Adanya keragaman pada poputasi yang dimiliki sangat memungkinkan melakukan seleksi untuk mendapatkan genotipe yang lebih baik Tujuan penelitian ini adalah mengevaluasi keragaman genetik pada fase benih beberapa genotipe pepaya koleksi Balitbu Tropika.

\section{BAHAN DAN METODE}

Penelitian dilakukan di KP.Sumani Balitbu Tropika, materi yang digunakan adalah 20 genotipe pepaya koleksi plasma nutfah Balitbu Tropika. Penelitian disusun dengan Rancangan Acak Kelompok dengan 4 ulangan, dengan menggunakan 20 genotipe pepaya hasil persilangan dan tetuanya. Benih dikecambahkan dengan cara merendam benih selama 24 jam dengan air hangat $\left(45^{\circ} \mathrm{C}\right)$, kemudian air ditiriskan Benih dikecambahkan pada tray perkecambahan dengan menggunakan media pasir halus dan steril. Benih ditanam ke dalam tray perkecambahan sedalam $1 \mathrm{~cm}$ kemudian ditutupi pasir, masing-masing tray berisi 25 benih, tray ditutup dan dipelihara kelembaban media dengan cara menyemprot dengan dengan air setiap hari. Pengamatan meliputi daya berkecambah, indeks vigor, potensi tumbuh maksimum, berat basah kecambah, berat kering kecambah dan panjang akar primer. Pengamatan dimulai pada hari ke 14 sampai hari ke 21 setelah dikecambahkan. Berat basah dan berat kering ditimbang pada hari ke 21. Daya berkecambah (DB) dihitung dengan rumus : jumlah benih yang berkecambah normal (pada hari ke 14 dan hari ke 21) dibagi jumlah benih yang dikecambahkan dikali $100 \%$. Indeks vigor (IV) dihitung dengan rumus: Jumlah benih yang berkecambah normal pada hari ke 14 dibagi jumlah benih yang dikecambahkan dikali $100 \%$. Potensi tumbuh maksimum (PTM) didapat dari menghitung jumlah benih yang berkecambah normal dan

Menurut Allard (1960), nilai duga heritabilitas didapatkan dengan menggunakan rumus:

$$
H=\frac{\sigma^{2} g}{\sigma^{2} f}
$$

Nilai duga heritabilitas diklasifikasikan menurut Mc Whirter (1979) dan Stanfield (1988), yaitu tinggi jika h2; 50\%, sedang jika $20 \%<$ h $2<50 \%$, dan rendah jika h $2<20 \%$.

\section{HASIL DAN PEMBAHASAN}

Hasil penelitian memperlihatkan keragaman viabilitas benih 20 genotipe pepaya yang diuji. Genotipe 20,26 dan 30 memiliki daya berkecambah (DB) > $90 \%$ sedangkan enam genotipe yang memilki daya berkecambah rendah < $50 \%$ yaitu genotipe dengan kode 2, 7, 9, 23, 24 dan 27 . Daya berkecambah merupakan tolok ukur viabilitas benih, menurut Sadjad (1994) viabilitas benih merupakan daya hidup benih yang ditunjukkan oleh fenomena pertumbuhan benih, gejala metabolisme, kinerja kromosom atau keadaan organel sitoplasma atau garis viabilitas. Viabilitas benih dapat diindikasikan oleh tolok ukur daya berkecambah (DB).

Nilai indeks vigor (IV) 20 genetipe pepaya berkisar $11-81 \%$, nilai IV didapat dari hitungan pada hari ke 14 setelah dikecambahkan. Nilai ini memperlihatkan kecepatan tumbuh benih, benih yang vigor tinggi adalah yang mampu tumbuh lebih cepat , normal dan serentak. Menurut Sadjad et al.(1999) vigor kekuatan tumbuh diukur dengan tolok ukur kecepatan tumbuh dan indeks vigor. Pertanaman yang normal menunjukkan kinerja pertumbuhan yang serempak, homogen serta pertumbuhannya cepat. Benih vigor menunjukkan kecepatan yang tinggi dalam proses pertumbuhannya apabila kondisi di sekelilingnya optimum untuk tumbuh dan proses metabolismenya tidak terhambat (Sadjad et al. 1999). Vigor benih tinggi dapat dilihat dari penampilan kecambah yang tahan terhadap berbagai faktor pembatas yang mempengaruhi pertumbuhan dan perkembangannya.

Potensi tumbuh maksimum (PTM) 20 genotipe yang diuji memperlihatkan variasi yang tinggi dimana nilai tertinggi PTM mencapai $100 \%$ dan terrendah 30\%. Nilai PTM merupakan viabilitas total dari suatu benih, hal ini menunjukkan adanya gejala kehidupan yang ditandai dengan proses pemunculan radikula dan pemanjangan hipokotil. Nilai potensi tumbuh akan lebih besar dibandingkan dengan daya berkecambah. Jika nilai PTM suatu genotipe tinggi maka selisih nilai PTM dengan nilai DB menggambarkan bahwa genotipe tersebut memiliki pesentase benih yang abnormal lebih banyak dibanding benih yang normal. Katagori benih abnormal antara lain radikula tidak berkembang, hipokotile tidak memanjang, daun pertama tidak bekembang, terdapatnya necrosis (ISTA,2010). 
Tabel 1. Keragaan Daya Berkecambah, Indeks Vigor (IV), Potensi Tumbuh Maksimal (PTM), Bobot Basah Kecambah Normal (BBKN), Bobot Kering Kecambah Normal (BKKN) dan Panjang Akar (PA) 20 Genotipe Pepaya

\begin{tabular}{cllcccr}
\hline $\begin{array}{c}\text { Kode } \\
\text { Genotipe }\end{array}$ & DB (\%) & IV (\%) & PTM (\%) & BBKN $(\mathrm{g})$ & BKKN (g) & PA (cm) \\
\hline 2 & $43,33^{\text {cd }}$ & $40,00^{\mathrm{b}-\mathrm{d}}$ & $46,67 \mathrm{a}-\mathrm{c}$ & 0,57 & $0,09 \mathrm{~cd}$ & 12,48 \\
4 & $63,33^{\text {a-d }}$ & $48,33^{\mathrm{a}-\mathrm{c}}$ & $63,33 \mathrm{a}-\mathrm{c}$ & 6,01 & $0,14 \mathrm{~cd}$ & 5,73 \\
7 & $33,33^{\mathrm{d}}$ & $11,67^{\mathrm{d}}$ & $46,67 \mathrm{a}-\mathrm{c}$ & 0,53 & $0,23 \mathrm{a}-\mathrm{d}$ & 23,54 \\
9 & $48,33^{\mathrm{b}-\mathrm{d}}$ & $36,67 \mathrm{~b}-\mathrm{d}$ & $56,67 \mathrm{a}-\mathrm{c}$ & 0,78 & $0,09 \mathrm{~cd}$ & 4,72 \\
11 & $66,67^{\mathrm{a}-\mathrm{d}}$ & $38,33 \mathrm{~b}-\mathrm{d}$ & $56,67 \mathrm{a}-\mathrm{c}$ & 0,73 & $0,12 \mathrm{~cd}$ & 23,53 \\
13 & $88,33^{\mathrm{a}}$ & $61,67 \mathrm{ab}$ & $60,00 \mathrm{a}-\mathrm{c}$ & 1,39 & $0,17 \mathrm{~b}-\mathrm{d}$ & 48,91 \\
15 & $70,00^{\text {a-c }}$ & $55,00 \mathrm{ab}$ & $56,67 \mathrm{a}-\mathrm{c}$ & 1,8 & $0,23 \mathrm{a}-\mathrm{d}$ & 27,93 \\
17 & $68,33^{\mathrm{a}-\mathrm{c}}$ & $58,33 \mathrm{ab}$ & $93,33 \mathrm{ab}$ & 1,1 & $0,18 \mathrm{~b}-\mathrm{d}$ & 36,94 \\
18 & $86,67^{\mathrm{a}}$ & $71,67 \mathrm{ab}$ & $100,00 \mathrm{a}$ & 1,54 & $0,24 \mathrm{a}-\mathrm{d}$ & 5,43 \\
19 & $78,33^{\text {ab }}$ & $73,33 \mathrm{ab}$ & $96,67 \mathrm{a}$ & 1,39 & $0,23 \mathrm{a}-\mathrm{d}$ & 33,53 \\
20 & $91,67^{\mathrm{a}}$ & $81,67 \mathrm{a}$ & $100,00 \mathrm{a}$ & $1,87 \mathrm{~b}$ & $0,28 \mathrm{a}-\mathrm{d}$ & 5,41 \\
22 & $60,00^{\mathrm{a}-\mathrm{d}}$ & $43,33 \mathrm{~b}-\mathrm{d}$ & $36,67 \mathrm{bc}$ & $4,85 \mathrm{~b}$ & $0,16 \mathrm{~cd}$ & 14,12 \\
23 & $48,33^{\mathrm{b}-\mathrm{d}}$ & $18,33 \mathrm{~cd}$ & $56,67 \mathrm{a}-\mathrm{c}$ & $0,83 \mathrm{~b}$ & $0,10 \mathrm{~cd}$ & 21,07 \\
24 & $48,33 \mathrm{~b}-\mathrm{d}$ & $40,00 \mathrm{~b}-\mathrm{d}$ & $16,67 \mathrm{c}$ & $7,06 \mathrm{~b}$ & $0,21 \mathrm{~b}-\mathrm{c}$ & 16,77 \\
25 & $63,33 \mathrm{a}-\mathrm{d}$ & $43,33 \mathrm{~b}-\mathrm{d}$ & $56,67 \mathrm{a}-\mathrm{c}$ & $0,99 \mathrm{~b}$ & $0,12 \mathrm{~cd}$ & 30,78 \\
26 & $91,67 \mathrm{a}$ & $81,67 \mathrm{a}$ & $86,67 \mathrm{ab}$ & $2,60 \mathrm{~b}$ & $0,33 \mathrm{a}-\mathrm{d}$ & 57,38 \\
27 & $33,33 \mathrm{~d}$ & $11,67 \mathrm{~d}$ & $63,33 \mathrm{a}-\mathrm{c}$ & $0,54 \mathrm{~b}$ & $0,06 \mathrm{~d}$ & 20,36 \\
28 & $85,00 \mathrm{a}$ & $68,33 \mathrm{ab}$ & $70,00 \mathrm{a}-\mathrm{c}$ & $2,10 \mathrm{~b}$ & $0,47 \mathrm{a}$ & 59,82 \\
29 & $88,33 \mathrm{a}$ & $61,67 \mathrm{ab}$ & $93,33 \mathrm{ab}$ & $15,02 \mathrm{a}$ & $0,43 \mathrm{ab}$ & 6,05 \\
30 & $93,33 \mathrm{a}$ & $63,33 \mathrm{ab}$ & $93,33 \mathrm{ab}$ & $2,37 \mathrm{~b}$ & $0,34 \mathrm{a}-\mathrm{c}$ & 25,61 \\
\hline
\end{tabular}

Keterangan : angka pada kolom yang sama pada masing-masing perlakuan diikuti huruf yang sama tidak berbeda nyata pada uji DMRT $\alpha 0.05$

Berat basah kecambah normal (BBKN) merupakan hasil proses metabolisme selama perkecambahan. Benih yang bermutu dapat dicirikan selain viabilitas dan vigor yang tinggi, juga memiliki kemampuan memanfaatkan cadangan makanan yang ada dalam benih menjadi bagian penting akar, batang dan daun. Menurut Ichsan (2006), komposisi akhir yang terdapat dalam benih ditentukan oleh kegiatan metabolisme selama masa pematangan biji, komposisi dalam biji atau benih akan mempengaruhi anabolisme dan katabolisme yang terjadi pada saat benih dikecambahkan. Berat kering kecambah normal merupakan gambaran akumulasi hasil metabolisme kecambah, menurut Jumini (2006) berat kering kecambah merupakan akumulasi hasil pertumbuhan selama proses perkecambahan. Genotipe dengan daya kecambah yang tinggi akan cendrung memiliki berat kering yang tinggi.

Tabel 2. Memperlihatkan nilai keragaman genetik dan heritabilitas pada karakter daya berkecambah, indeks vigor, potensi tumbuh maksimum, berat basah dan berat kering kecambah serta panjang akar.
Pada tabel 2 ragam genetik benih pada karakter DB, IV dan yang diuji luas, sedangkan karakter PTM,BK dan PA sempit. Ragam genetik yang luas memberi peluang untuk memudahkan seleksi genotipe berdasarkan viabilitas dan vigor benih. Menurut Bedell ( 1998) faktor genetik yang mempengaruhi vigor benih adalah pola dasar perkecambahan dan pertumbuhan yang merupakan bawaan genetik dan berbeda antara satu spesies dan spesies lain. Selanjutnya menurut Budiyanti (2014) keragaman genetik yang luas untuk beberapa karakter pada populasi ini disebabkan latar belakang genetik populasi yang berbeda Ragam genetik yang luas menunjukkan pengaruh faktor genetik lebih besar dari pada faktor lingkungan.

Mutu fisik dan fisiologis benih erat hubungannya dengan faktor genetis, pertumbuhan dan lingkungan. Susunan dasar genetik atau pewarisan yang dibawa oleh benih menentukan potensi penampilan keturunannya (Schmidt, 2000). Pada tahap awal seleksi untuk mendapatkan suatu varietas unggul perlu didapatkan karakter 
mutu fisiologis benih yang baik yang tercermin dengan nilai heritabilitas yang tinggi pada karakter tersebut.

Tabel 2. Ragam Genetik dan Heritabilitas Karakter Daya Berkecambah, Indeks Vigor (IV), Potensi Tumbuh Maksimal (PTM), Bobot Basah (BB), Bobot Kering (BK) dan Panjang Akar (PA) 20 Genotype Pepaya

\begin{tabular}{|c|c|c|c|c|c|c|c|}
\hline Karakter & $\begin{array}{l}\text { Ragam } \\
\text { Genotipe }\end{array}$ & $\begin{array}{c}\text { Ragam } \\
\text { Feno } \\
\text { tipe }\end{array}$ & $\begin{array}{c}\text { 2x sd } \\
\text { Ragam } \\
\text { Genetik }\end{array}$ & $\begin{array}{l}\text { Kriteria } \\
\text { Ragam } \\
\text { genetik }\end{array}$ & $\begin{array}{l}\text { F Hit } \\
\text { Perk }\end{array}$ & $\begin{array}{l}\text { Herita } \\
\text { bilitas }\end{array}$ & $\begin{array}{c}\text { Kriteria } \\
\text { heritabi } \\
\text { litas }\end{array}$ \\
\hline $\begin{array}{l}\text { Daya } \\
\text { berkecambah (\%) }\end{array}$ & 902,43 & 1202,19 & 251,34 & luas & $4,01^{\star \star}$ & 0,75 & tinggi \\
\hline Indeks vigor (\%) & 974,86 & 1333,22 & 279,45 & luas & $3.72^{\star *}$ & 0,73 & tinggi \\
\hline $\begin{array}{l}\text { Potensi Tumbuh } \\
\text { Maksimum (\%) }\end{array}$ & 743,16 & 1645,18 & 364,21 & sempit & $1.82^{\mathrm{tn}}$ & 0,45 & sedang \\
\hline Bobot Basah (g) & $2,3 \times 107$ & $\begin{array}{l}38008 \\
862,01\end{array}$ & 8140000,8 & luas & $2.51^{\star \star}$ & 0,60 & tinggi \\
\hline Bobot Kering (g) & 0,02 & 0,04 & 0,0088 & sempit & $2.14^{*}$ & 0,50 & sedang \\
\hline $\begin{array}{l}\text { Panjang Akar } \\
(\mathrm{mm})\end{array}$ & 2007150885 & $\begin{array}{r}12002 \\
973 \\
059,21\end{array}$ & $\begin{array}{r}2884202579 \\
32\end{array}$ & sempit & $1.20^{\text {tn }}$ & 0,17 & rendah \\
\hline
\end{tabular}

Heritabilitas dapat diartikan rasio ragam genotipe terhadap ragam fenotipe (Sjamsudin, 1990). Heritabilitas sering juga dipakai sebagai tolok ukur kemajuan genetik yang dapat diharapkan dalam suatu program seleksi (Allard, 1960). Tabel 2 .memperlihatkan nilai DB, IV dan BB memiliki nilai heritabilitas yang tinggi,sedangkan pada karakter panjang akar nilai duga heritabilitas rendah, hal ini menggambarkan bahwa karakter panjang akar lebih dipengaruhi faktor lingkungan dibandingkan dengan faktor genetik.

Menurut Nasir (2001) heritabilitas dalam arti luas dapat dianggap sebagai suatu batas dugaan tertinggi dari heritabilitas dalam arti sempit. Oleh karena itu, selama heritabilitas dalam arti sempit dapat dihitung, nilai heritabilitas dalam arti luas tidak banyak digunakan, bila nilai heritabilitas arti sempit tinggi, maka metode seleksi yang paling tepat digunakan adalah seleksi massa sebaliknya apabila rendah sebaiknya digunakan seleksi silsilah.

\section{KESIMPULAN DAN SARAN}

1. Keragaman genetik viabilitas dan vigor benih pepaya sangat tinggi.

2. Nilai duga heritabilitas berkisar dari sedang hingga tinggi kecuali panjang akar, pada karakter daya berkecambah, indek vigor dan bobot basahnya, karakter tersebut diwariskan karena heritabilitasnya juga tinggi .

3. Seleksi dapat dilakukan dengan karakter viabilitas dan vigor benih.

\section{DAFTAR PUSTAKA}

Akram , M., S. Ajmal, M. Munir. 2007. Inheritance of Traits Related to Seedling Vigor and Grain Yield in Rice (Oryza sativa). Pak. J. Bot. 39 (1): 3745

Allard, R.W. 1960. Dasar-dasar Pemuliaan Tanaman. Diterjemahkan oleh Manna dan Mulyani tahun 1998. PT Rieneka Bina Aksara.

Budiyanti,T dan Sunyoto.2014. Pendugaan Heritabilitas dari 15 Genotipe Pepaya (Carica papaya I.) Pada Dua Periode Musim Panen. Jurnal Agroteknologi, Vol. 4. No. 2

Baktisari Atika. 2009 . Keragaman Karakter Terkait Vigor Daya Simpan Benih Kedelai (Glycine max L. Merill). Tesis IPB.

Baihaki, A 1996. Prospek penerapan "Breeder Right" di Indonesia, dalam Sumarno ,Hari Bowo, B. Priyanto, Nova Agustin dan Widi Wiryani (Ed). Prosiding Simposium Pemuliaan Tanaman IV. Vol V. (9):1-16. Univ.Pembangunan Nsional. Surabaya.

Copeland Lo dan McDonald MB. 2001. Principles of Seed Science and Technology. 4 th edition. Kluwer Acad. Publish. London.

Divakara, B.N., A.S. Alur, S. Tripati. 2010. Genetic variability and relationship of pod and seed traits in Pongamia Pinnata (L.) Pierre., a potential agroforestry tree. International Journal of Plant Production. 4 (2): 1735-8043

Ekowahyuni L.P, Surjono H.S, S. Sujiprihati, M.R .Suhartanto, M. Syukur 2013. 
Evaluasi Vigor daya Simpan Benih pada Berbagai Genotipe Cabai (Capsicum annuum I.) dengan Metode Pengusangan Cepat. E-Journal WIDYA Kesehatan Dan Lingkungan Volume 1.

Fehr, W.R. 1987. Principles of cultivar development. Volume I: theory and technique. Macmillan Pub, New York.

Ichsan Cut Nur . 2006. Uji viabilitas dan vigor benih beberapa varietas padi (oryza sativa I.) yang diproduksi pada temperatur yang berbeda selama kemasakan. J. Floratek $2: 37-42$

Isemura, T., A. Kaga, S. Konishi, T. Ando, N.Tomooka, O.K. Han, D.A. Vaughan. 2007. Genome Dissection of Traits Related to Domestication in Azuki Bean (Vigna angularis) and Comparison with other Wann-season Legumes. Annals of Botany. 100: 1053-1071

Jumini. (2006). Viabilitas Benih Sebagai Indikator Tingkat Pencemaran Lingkungan J. Floratek $2: 12-18$.

Marwoto. 2003. Keragaan Resistensi Beberapa Genotipe Benih Kedelai terhadap Deraan Cuaca: I. pengaruh Metode Penapisan. Jurnai Akta Agrosia. 6 (I) : 18-22

Nasir, M. 2001. Keragaman Genetik Tanaman, hal 64. Dalam: Makmur, A (Ed). Pengantar Pemuliaan Tanaman. Direktorat Jenderal Pendidikan Tinggi Departemen Pendidikan Nasional. Jakarta.

Ningsih Sadjad, S. 1994. Panduan Pembinaan Mutu Benih Tanaman Kehutanan di Indonesia. Lembaga Afiliasi. IPB. 300 hlm.

Sadjad S, Murniati E, Ilyas S.1999. Parameter pengujian vigor benih, Grassindo bekerjasama dengan Perum Sang Hyang Seri. Jakarta.

Saeidi , G. 2008. Genetic variation and heritability for germination, seed vigour and field emergence in brown and yellow-seeded genotypes of flax. International Journal of Plant Production 2 (I): 15-22

Schmidt, L. 2000. Pedoman Penanganan Benih Tanaman Hutan Tropis dan Sub Tropis. Terjemahan Direktorat Jenderal Rehabilitasi Lahan dan Perhutanan Sosial, Kementerian Kehutanan. Jakarta.

Umar Sudirman. 2012. Pengaruh Pemberian Bahan Organik terhadap Daya Simpan Benih Kedelai (Glycine max (L.) Merr). Berita Biologi 11(3)
Wirnas Desta, Widajatil Eni, Atika Bakti Sari .2012. Pewarisan Karakter Daya Simpan Benih Kedelai pada Kondisi Suhu Ruang. J. Agroekoteknolog. Vol. 4 No.1 
Keragaman Viabilitas Benih 20 Genotipe (Noflindawati, dkk) 